\title{
SISTEM MONITORING PENGGUNAAN DAYA LISTRIK BERBASIS INTERNET OF THINGS PADA RUMAH DENGAN MENGGUNAKAN APLIKASI BLYNK
}

\author{
Maria Febrianti Pela ${ }^{1}$, Rully Pramudita ${ }^{2}$ \\ ${ }^{1,2}$ Teknik Informatika \\ ${ }^{1,2}$ Universitas Bina Insani, Bekasi, Indonesia \\ Correspondence email: rullypramudita@binainsani.ac.id
}

Article history: $\quad$ Submission date: Juni 16, 2021 Revised date: Juni 27, 2021 Accepted date: Juni 30, 2021

\begin{abstract}
All work and human needs are highly dependent on the presence of electrical energy, especially on household needs. Human negligence in using electrical energy will cause waste in the use of electrical energy which causes soaring payments among households. This study aims to examine the application of monitoring the electrical power used in the connection of these devices remotely via the internet. The system can be implemented using NodeMCU ESP8266, PZEM-004T sensor, Liquid Crystall I2C, and the Blynk application as a user interface system on a smartphone. To be able to monitor through the Blynk application, the user must be connected to the internet and the microcontroller must be connected to the internet network. This system using the internet network will make it easier to monitor electrical power in electronic devices at home every day. The results of this study are the prototype of the electrical power monitoring system using the Blynk application can help and facilitate homeowners in monitoring electrical power when the homeowner is not at home.
\end{abstract}

Keywords : Internet Of Things, PZEM-004T, NodeMCU, Blynk.

\begin{abstract}
ABSTRAK
Semua pekerjaan dan kebutuhan manusia sangan tergantung dengan adanya energi listrik terutama pada kebutuhan rumah tangga. Kelalaian manusia dalam menggunakan energi listrik akan menyebabkan keborosan pada pemakaian energi listrik yang menyebabkan pembayaran yang melonjak dalam kalangan rumah tangga. Penelitian dilakukan untuk mengkaji penerapan memonitoring daya listrik yang terpakai pada alat tersebut dari jarak jauh melalui koneksi internet. Sistem dapat diimplementasikan menggunakan NodeMCU ESP8266, sensor PZEM004T, Liquid Crystall I2C, dan aplikasi Blynk sebagai user interface sistem pada smartphone. Untuk dapat memantai melalui aplikasi Blynk pengguna harus terkoneksi internet dan mikrokontroler harus terhubung oleh jaringan internet. Sistem dengan menggunakan jaringan internet ini akan lebih mudah memantai daya listrik pada perangkat elektronik pada rumah setiap harinya. Hasil dari penelitian ini adalah Prototype sistem monitoring daya listrik menggunaan aplikasi Blynk ini dapat membantu dan mempermudah pemilik rumah dalam memonitoring daya listrik pada saat pemilik rumah sedang tidak berada dirumah.
\end{abstract}

Kata Kunci : Internet Of Things, PZEM-004T, NodeMCU, Blynk.

\section{PENDAHULUAN}

Pada perkembangan teknologi yang semakin maju maka diperlukannya kesadaran kita untuk berusaha menerapkan teknologi tepat guna yang dapat bermanfaat bagi kehidupan masyarakat. Secara umum teknologi yang dapat menunjang kehidupan dari segi sosial ekonomi. Dengan tingkat ekonomi yang masih buruk, dan juga negara dengan sistem jaringan listrik yang masih kurang baik.
Sesuai dengan Undang - Undang Nomor 30 Tahun 2009 tetang ketenagalistrikan yang mengatur mengenai peningkatan tarif dasar listrik dalam rumah tangga maupun industri kecil yang dikarenakan pencabutan subsidi listrik.

Umumnya penggunaan listrik pada rumah setiap perangkat langsung terhubung ke Kwh Meter. Maka dengan itu saat pemakaian listrik di rumah melebihi kapasitas yang terpakai akan mengalami overload pemakaian listrik dan listrik akan padam di rumah tersebut. 
Apabila sering mengalami overload listrik akan membuat perangkat elektronik rusak dan akan menambah pengeluaran biaya sehingga pengeluaran dalam rumah tangga akan semakin banyak. Dengan penggunaan listrik pada rumah tangga tidak terkontrol sehingga dapat membuat tagihan pada rumah tangga sangat tinggi atau melonjaknya tagihan listrik, tidak adanya sistem monitoring penggunaan daya listrik pada rumah saat perangkat elektronik rumah tangga di gunakan tanpa batas membuat resiko kerugian materil. Dan dengan memanfaakan teknologi yang ada saat ini, maka memungkinkan untuk membuat sistem monitoring dalam penggunaan daya listrik. Pemilik rumah dapat mengetahui melalui aplikasi Blynk jika terjadinya lonjakan biaya pada setiap perangkat elektronik dan bisa dibatasi dengan cara mematikan perangkat jika tidak terpakai. Serta tidak perlu khawatir akan lonjakan biaya tagihan listrik setiap bulannya, karena akan didukung dengan cara memonitoring penggunaan daya listrik pada rumah.

Peralatan rumah tangga, seperti kulkas, televisi, dispenser, lampu dan AC merupakan daya konsumsi pelanggan PLN paling besar. [Budi Prayitno, Pritasari Palupiningsih, 2019].

Berdasarkan penelitian diatas dapat disimpulkan monitoring penggunaan daya listrik ini digunakan oleh pemilik rumah untuk lebih menghemat biaya tagihan listrik pada setiap bulannya dan memberikan kenyamanan dalam segi ekonomi. Dalam kasus ini banyak pemilik rumah yang setiap bulannya mengalami kenaikan dalam pembayaran listrik karna tidak terkendali biaya pemakaian listrik pada setiap perangkatnya.

Berdasarkan rumusan masalah tersebut adapun tujuan yang akan dibahas yaitu:

Dengan membuat sistem monitoring daya listrik pada rumah agar pema-kaian listrik lebih terkendali setiap harinya. Adanya alat monitoring penggunaan energi listrik berdasarkan jumlah tegangan pada perangkat-perangkat elektronik, sehingga dari jumlah tersebut akan mempengaruhi pengguna untuk lebih menghemat pemakaian energi listrik agar tidak terjadi pemborosan. Mengetahui kapasitas KWh meter listrik pada rumah sehingga jika sudah overload pemakaian listrik maka bisa dikurangi pemakaian setiap perangkat elektronik yang ada di rumah dengan melihat nya di alat sistem monitoring daya listrik.

Dalam penelitian ini, kurang lebihnya terinspirasi dan mereferensi dari penelitianpenelitian sebelumnya yang berkaitan dengan latar belakang pada penelitian ini, antara lain:

Penggunaan daya listrik di rumah tangga selama ini hanya dapat dilihat melalui alat ukur kWh meter yang didistribusikan oleh PLN yang menampilkan hasil kumulatif penggunaan daya. Tujuan penelitian ini adalah melakukan monitoring daya listrik alat elektronik rumah tangga menggunakan arduino NodeMCU ESP8266 secara real-time. Alat bekarja dengan baik serta mampu membaca arus dan daya pada saat pengkondisian $O n$, tingkat akurasi alat berkisar 96\% - 98\% (Pangestu et al., 2019).

Penghematan konsumsi daya listrik di rumah akan berdampak pada konsumsi daya secara nasional. Pada penelitian sebelumnya menunjukkan monitoring konsumsi daya listrik di rumah akan berdampak terhadap penghematan konsumsi listrik hingga 30\% (Santoso et al., 2018). Monitoring daya listrik dapat dioptimalkan dengan memanfaatkan teknologi Mikrokontroller (Dalimunthe, 2018).

Dapat disimpulkan bahwa penelitian ini dilakukan untuk menciptakan serta mengembangkan suatu perangkat berbasis Internet Of Things untuk kegiatan sehari-hari pada rumah tangga. Dari salah satu abstrak diatas menyebutan sebuah penggunaan daya listrik di rumah tangga selama ini hanya dapat dilihat melalui alat ukur $\mathrm{kWh}$ meter yang hanya didistribusikan oleh PLN. Penggunaan alat tersebut tidak memberikan informasi tentang berapa besar daya listrik yang digunakan secara real-time. Dalam penelitian ini dimana alat yang dikembangkan dapat membantu setiap rumah tangga dalam penghematan pemakain listrik pada rumah yang dapat dikontrol melalui sebuah aplikasi Blynk yang terkoneksi oleh internet. Dengan itu dapat mengecek jumlah daya yang terpakai dari jarak jauh dan berapa daya yang terpakai setiap harinya agar bisa lebih berhemat dalam setiap bulannya.

NodeMCU adalah sebuah platform IoT yang bersifat open source. dan juga firmware yang digunakan yang menggunakan bahasa pemrograman scripting Lua. Istilah NodeMCU sebenarnya mengacu pada firmware yang digunakan daripada perangkat keras development kit. NodeMCU bisa dianalogikan sebagai board Arduino-nya ESP8266. NodeMCU telah menggabungkan ESP8266 ke dalam sebuah board yang kompak dengan berbagai fungsi layaknya mikrokontroler ditambah juga dengan kemampuan akses terhadap Wifi juga chip komunikasi USB to Serial sehingga untuk memprogramnya hanya diperlukan ekstensi kabel data mikro USB (Satriadi et al., 2019).

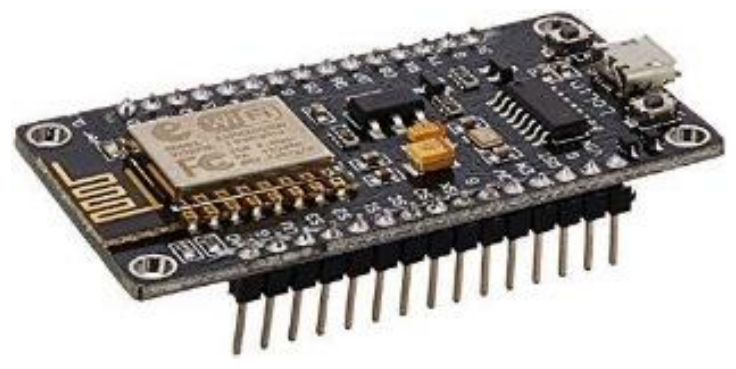

Sumber: (Satriadi et al., 2019)

Gambar 1. NodeMCU ESP8266 
NodeMCU ESP8266 merupakan modul mikrokontroler yang didesain dengan ESP8266 di dalamnya. ESP8266 berfungsi untuk konektivitas jaringan Wifi antara mikrokontroler itu sendiri dengan jarigan Wifi. NodeMCU berbasis bahasa pemograman Lua namun dapat juga menggunakan Arduino IDE untuk prmogramannya (Pangestu et al., 2019).

Dari penjelasan diatas, dapat disimpulkan bahwa NodeMCU adalah firmware interaktif berbasis LUA dan dapat juga diprogram menggunakan bahasa $\mathrm{C}$ menggunakan arduino IDE. NodeMCU dapat dioperasikan jika terhubung Wifi sehingga dapat mengirikan informasi informasi pada prototype sistem monitoring daya listrik yang akan dikirimkan ke server.

PZEM-004T adalah sensor yang dapat digunakan untuk mengukur tegangan rms, arus rms dan daya aktif yang dapat dihubungkan melalui arduino ataupun platform open source lainnya. Modul ini terutama digunakan untuk mengukur tegangan AC, arus, daya aktif, frekuensi, faktor daya dan energi aktif, modul tanpa fungsi tampilan, data dibaca melalui interface TTL. Interface TTL dari modul ini adalah interface pasif, membutuhkan catu daya eksternal 5V, yang berarti ketika berkomunikasi, keempat port harus terhubung $(5 \mathrm{~V}$, RX, TX, GND) jika tidak ia tidak dapat berkomunikasi (innovatorsguru, n.d.) (Anwar et al., 2020).

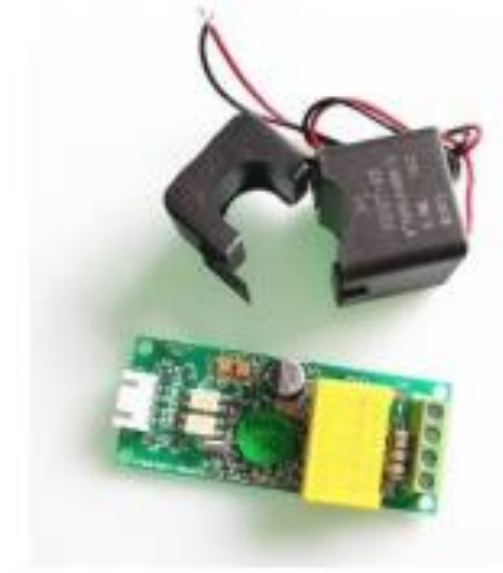

Sumber: (Anwar et al., 2020)

Gambar 2. PZEM $004 T$ V03

Modul PZEM-004T adalah sebuah modul sensor multifungsi yang berfungsi untuk mengukur daya, tegangan, arus dan energi yang terdapat pada sebuah aliran listrik. Modul ini sudah dilengkapi sensor tegangan dan sensor arus (CT) yang sudah terintegrasi (Habibi et al., 2017).
Dari penjelasan diatas, dapat disimpulkan PZEM-004T adalah hardware yang berfungsi untuk mengukur parameter dari tegangan, arus, daya aktif, dan konsumsi daya (kwh). Modul ini juga melayani semua persyaratan dasar pengukuran PZEM-004T ini sebagai papan terpisah.

ProjectBoard atau yang sering disebut sebagai BreadBoard adalah dasar konstruksi sebuah sirkuit elektronik dan merupakan prototipe dari suatu rangkaian elektronik. Breadboard banyak digunakan untuk merangkai komponen, karena dengan menggunakan breadboard, pembuatan prototipe tidak memerlukan proses menyolder (Andri Firmansyah, 2019).

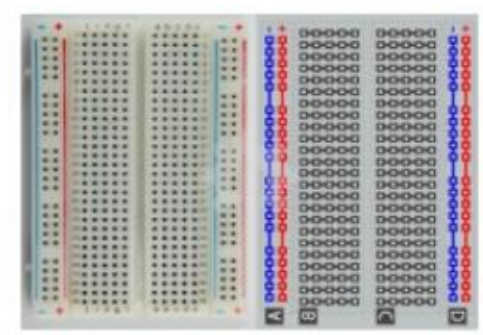

Sumber: (Andri Firmansyah, 2019) Gambar 3. Breadboard

Breadboard adalah merupakan papan ujicoba rangkaian elektronika yang pada umumnya dipergunakan oleh pemula yang ingin mencoba. Papan dengan konstruksi berlubang sesuai untuk menancapkan komponen tanpa di hubungkan secara permananen (Deny Nusyirwan, 2019).

Dari penjelasan diatas, dapat disimpulkan bahwa breadboard merupakan rangkaian elektronik dalam sebuah prototype tanpa harus adanya penyolderan.

\section{METODOLOGI PENELITIAN}

Pada penelitian ini metode yang digunakan dalam pengembangan alat Internet Of Things adalah metode pengembangan Prototype. Model prototype mampu menawarkan pendekatan yang paling baik dalam hal efesiensi suatu algoritma, kemampuan perangkat lunak untuk beradaptasi dengan sistem operasi yang akan digunakan. Tujuannya yaitu membantu pengembangan stekholder untuk memahami lebih baik apa yang di kembangkan saat spesifikasi kebutuhan belum jelas. [Pressman, 2010] Pada metode pengembangan prototype ini juga berfungsi sebagai kerangka kerja yang menjelaskan bagaimana proses penelitian ini berlangsung sehingga penelitian ini dapat dikerjakan sesuai dengan tahapan yang berurutan. 


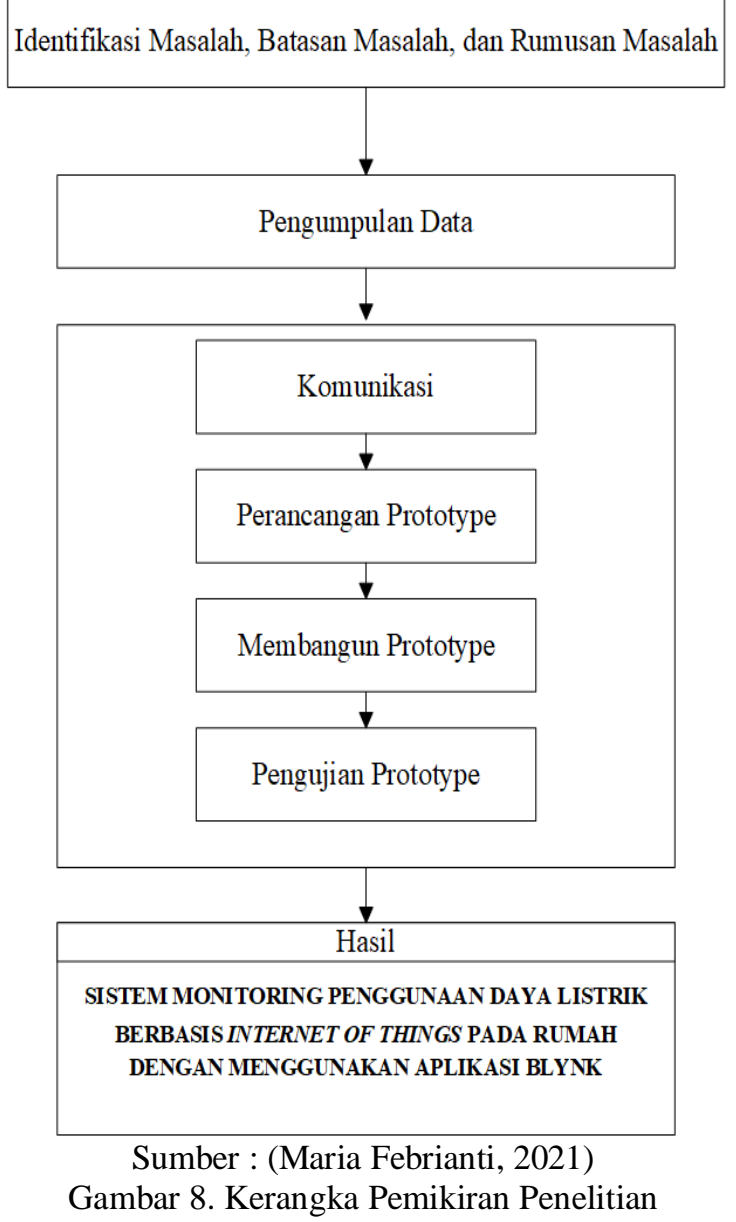

Keterangan Gambar 8. Bahwa pada tahap awal penelitian dimulai dari tahap Identifikasi masalah, Batasan masalah dan Rumusan masalah, tahap ini dilakukannya tahap identifikasi terhadap permasalahan yang terkait penelitian, dan pembatasan ruang lingkup masalah atau upaya untuk membatasi sebuah ruang lingkup dalam masalah yang terlalu luas atau lebar sehingga sebuah penelitian bisa lebih fokus untuk dilakukan, pada tahap ini maslaah yang terkait dengan sebuah objek penelitian akan dikaji untuk dapat dirumuskan sehingga pada penelitian dapat dilakukan, tahap selanjutnya adalah pengumpulan data dimana pada tahap ini akan dilakukan pengumpulan data dan informasi menggunakan cara Studi Pustaka untuk mengumpulkan informasi terkait sistem Monitoring Daya Listrik. Tahap selanjutnya ialah komunikasi, pada tahapan ini akan dilakukannya sebuah diskusi antara klien dan developer terkait tentang ruang lingkup dan tujuan dari metode prototype ini.
Tahap berikutnya Perancangan Prototype, pada tahap ini akan dilakukannya perancangan dengan cara cepat dan mewakili semua aspek dalam membuat kebutuhan user, kebutuhan perangkat keras (Hardware), dan kebutuhan perangkat lunak (Software) pada sistem Monitoring Daya Listrik, selanjutnya tahap Membangun Prototype Tahap ini merupakan tahapan dimana kita akan mendesain dan membangun sebuah perangkat Monitoring Daya Listrik Pada Rumah Berbasis (Inernet Of Things) Dengan Menggunakan Aplikasi Blynk sesuai dengan apa yang sudah dirancang sebelumnya, tahap selanjutnya dengan Menguji Coba Prototype tahap ini dilakukan pengujian sistem berdasarkan Black Box Testing pada perangkat yang sudah dibuat agar dapat dievaluasi dengan cepat, selanjutnya adalah hasil, Tahap ini merupakan tahap akhir, dimana Prototype Monitoring Daya Listrik Pada Rumah Berbasis (Inernet Of Things) dengan Menggunakan Aplikasi Blynk sudah selesai dirancang dan dibuat dengan baik dan benar sesuai dengan fase dan metode pengembangan yang digunakan yaitu metode pengembangan Prototype.

\section{HASIL DAN PEMBAHASAN}

Bagian hasil penelitian berisi paparan hasil analisis yang berkaitan dengan pertanyaan penelitian. Setiap hasil penelitian harus dibahas. Pembahasan berisi hasil dan perbandingan dengan teori dan/atau hasil penelitian sejenis.

Pada tahap pengumpulan data dan komunikasi menggunakan cara Studi Pustaka dan berdiskusi untuk mengumpulkan sebuah informasi terkait dengan sistem infromasi Monitoring Daya Listrik Pada Rumah Berbasis (Inernet Of Things) Dengan Menggunakan Aplikasi Blynk melalui buku-buku, literatur, jurnal, dan internet agar mendapatkan data dan informasi tentang cara sistem berjalan pada monitoring daya listrik.

Berdasarkan informasi mengenai sistem yang sedang berjalan didapatkan sebuah user requirment untuk mempermudah dalam monitoring daya listrik pada saat kita sedang berada diluar rumah yang terkadang sulit untuk mengontrol daya listrik pada setiap perangkat elektronik. Maka dibuatlah perencanaan sistem pada tahap kedua ini dimana dalam membangun sistem monitoring daya listrik ini dibagi menjadi tiga desain perencaan kebutuhan, yaitu kebutuhan perangkat user atau pengguna, kebutuhan perangkat keras, dan kebutuhan perangkat lunak. Kebutuhan sistem yang diinginkan pengguna dapat dilihan pada tabel 1 . 
Tabel 1. Kebutuhan Pengguna

\begin{tabular}{|c|c|c|}
\hline No & Kebutuhan & Deskripsi \\
\hline 1 & Kipas Angin & $\begin{array}{l}\text { Perangkat elektronik } \\
\text { untuk mengukur daya, } \\
\text { arus, power, dan } \\
\text { current. }\end{array}$ \\
\hline 2 & Setrika & $\begin{array}{l}\text { Perangkat elektronik } \\
\text { untuk mengukur daya, } \\
\text { arus, power, dan } \\
\text { current. }\end{array}$ \\
\hline 3 & Lampu & $\begin{array}{l}\text { Perangkat elektronik } \\
\text { untuk mengukur daya, } \\
\text { arus, power, dan } \\
\text { current. }\end{array}$ \\
\hline 4 & Handphone & $\begin{array}{l}\text { Alat untuk } \\
\text { menyimpan aplikasi } \\
\text { Blynk. }\end{array}$ \\
\hline 5 & Jaringan Internet & $\begin{array}{l}\text { Untuk } \\
\text { menghubungkan dari } \\
\text { Blynk kepada } \\
\text { nodeMCU ESP8266. }\end{array}$ \\
\hline
\end{tabular}

Sumber: (Maria Febrianti Pela, 2021)

Berikut ini yaitu perancangan prototype dalam tahapan ini terdapat tabel perangkat keras yang digunakan untuk mendukung Sistem Monitoring Penggunaan Daya Listrik Berbasis Internet Of Things Pada Rumah Dengan Menggunakan Aplikasi Blynk. Yang dapat dilihat pada tabel 2.

Tabel 2. Kebutuhan Perangkat Keras.

\begin{tabular}{clc}
\hline No & \multicolumn{1}{c}{ Komponen } & Jumlah \\
\hline 1 & NodeMCU Esp8266 & 1 \\
2 & $\begin{array}{l}\text { Sensor Arus PZEM- } \\
\text { 004T }\end{array}$ & 1 \\
3 & Breadboard & 1 \\
4 & Liquid Crystal I2C & 1 \\
\hline & Sumber: (Maria Febrianti Pela, 2021)
\end{tabular}

Berikut ini merupakan tabel perangkat lunak yang digunakan untuk mendukung Sistem Monitoring Penggunaan Daya Listrik Berbasis Internet Of Things Pada Rumah Dengan Menggunakan Aplikasi Blynk. Yang dapat dilihat pada tabel 3 .

Tabel 3. Kebutuhan Perangkat Lunak

\begin{tabular}{cll}
\hline No & Software & \multicolumn{1}{c}{ Spesifikasi } \\
\hline 1 & Operating & - Windows 10 \\
& System (OS) & -64 bit \\
2 & Arduino IDE & - Versi 1.8.12 \\
3 & Aplikasi & - Versi 2.27.29 \\
& Blynk & \\
\hline \multicolumn{3}{c}{ Sumber: (Maria Febrianti Pela, 2021) }
\end{tabular}

Selanjutnya ada pemodelan sistem dimana menodelan sistem ini secara keseluruhan menjelaskan model prototype yang nantinya akan dibangun. Pemodelan sistem ini digambarkan dsalam bentuk flowchart (diagram alur) yaitu seperti gambar dibawah ini.

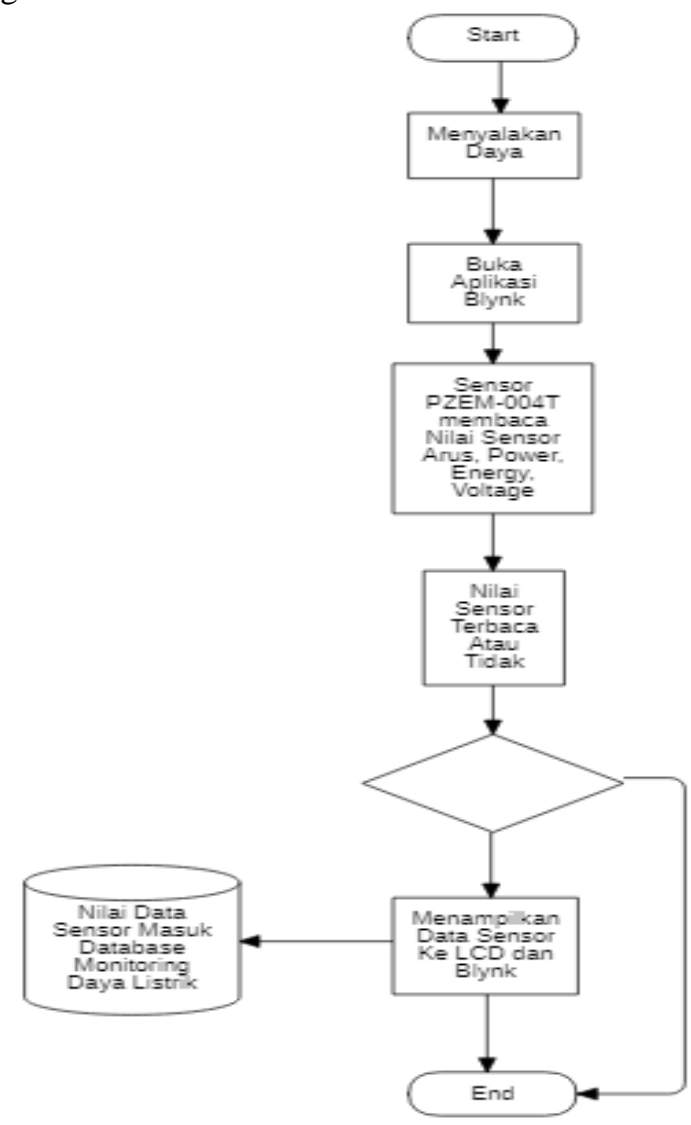

Sumber : (Maria Febrianti, 2021)

Gambar 9. Flowchart Pemodelan Prototype

Kemudian ada perancangan perangkat keras dimana perancangan ini merupakan rangkaian yang nantinya akan digunakan dalam sistem Monitoring Penggunaan Daya Listrik Berbasis Internet of Things Pada Rumah Dengan Menggunakan Aplikasi Blynk.Yang digambarkan dalam bentuk diagram wiring digital.

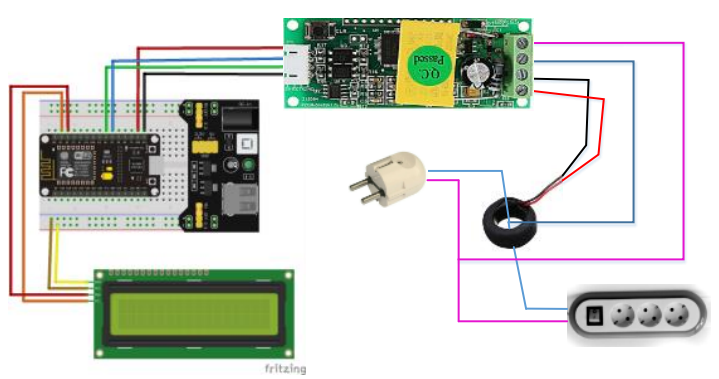

Sumber : (Maria Febrianti, 2021)

Gambar 10. Kerangka Pemikiran Penelitian Pada gambar 10. Merupakan gambar 
rangkaian perangkat keras yang terdiri dari perancangan rangkaian mikrokontroler NodeMCU ESP8266 yang berfungsi sebagai pengubung komponen lain dengan aplikasi Blynk melalui koneksi jaringan internet atau wifi. Sebagai mikrokontroler pada prototype monitoring daya listrik untuk memprogram membaca arus, energy, voltage, dan power pada perangkat elektronik.

Kemudian perancangan rangkaian sensor PZEM-004T berfungsi untuk membaca dari keseluruhan arus yang terhubung pada stop kontak atau terminal listrik. Dan perancangan pada power supplu untuk menambahkan tegangan pada Liquid Crystall Display I2C.

Dalam rancangan perangkat lunak ini digambarkan alur dari skema perangkat lunak secara keseluruhan, sehingga tergambar jelas bagaimana alur dari sistem Monitoring Daya Listrik Berbasis Internet Of Things Pada Rumah Dengan Menggunakan Aplikasi Blynk Dalam menggambarkan alur dari skema perangkat lunak dapat digambarkan sengan menggunakan use case diagram seperti pada gambar dibawah ini.

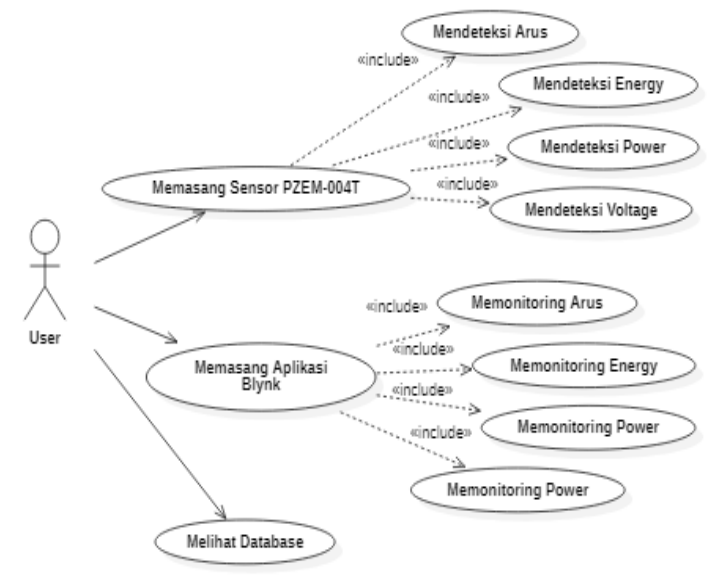

Sumber : (Maria Febrianti, 2021)

Gambar 11. Use Case Monitoring Daya Listrik

Pada gambar 11. Menjelaskan skenario dari si pengguna dengan sistem monitoring daya listrik. Dimulai dari memasang sensor PZEM-004T maka akan terhitung berapa daya dan arus yang dikeluarkan oleh perangkat elektronik secara keseluruhan. Dengan memonitoring melalui aplikasi blynk si pengguna dapat lebih mudah dan akan tersimpan pada database yang dapat dilihat melalui website.

Pada tahap selanjutnya yaitu Membangun Prototype dimana tahapan ini membangun sebuah prototype yang sudah dirancang pada tahapan sebelumnya. Berikut adalah implementasi perancangan perangkat keras (hardware) yang digunakan untuk monitoring daya listrik pada rumah sebagai berikut:

a. NodeMCU Dan Modul Power Supply

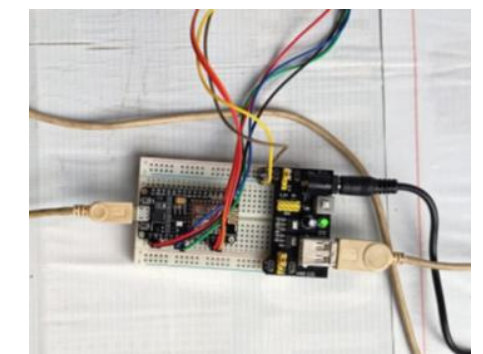

Sumber : (Maria Febrianti, 2021)

Gambar 12. NodeMCU dan Modul Power Supply

NodeMCU dipasang pada breadboard atau protoboard bersebelahan dengan power supply. Dan kabel-kabel yang terhubung dengan sensor PZEM004T dan LCD.

b. Membangun Perangkat Sensor PZEM-004T

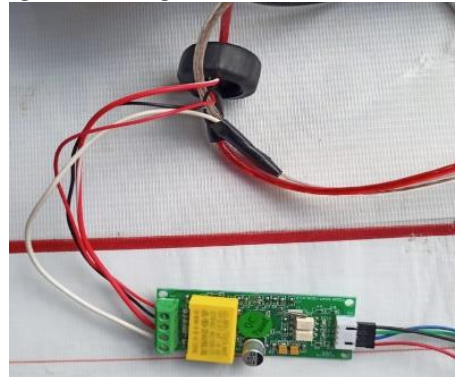

Sumber : (Maria Febrianti, 2021)

Gambar 13. Membangun Perangkat Sensor PZEM004T

Sensor Pzem akan di pasangkan kabel sesuai pin yang tertera pada sensor tersebut. Kabel dari stop kontak dibuat cabang yang nantinya akan terhubung pada sensor PZEM-004T dan salah satu kabel pada stop kontak akan di masukan ke cating dari sensor PZEM-004T untuk dapat mengukur arus dari keseluruhan perangkat elektronik.

Tahap selanjutnya adalah tahap uji coba (Testing) pada tahapan ini berisi proses pengujian sistem monitoring daya listrik pada rumah berbasis internet of things dengan menggunakan aplikasi blynk. Setelah diuji coba pemilik rumah akan dapat memonitoring daya listrik menggunakan aplikasi blynk dimanapun dan kapanpun ketika aat mikrokontroler terhubung ke jaringan. Hasil dari pengujian menggunakan konsep pengujian black box sistem, yaitu pengujian dengan mengamati secara fungsi dari perangkat dan pengendalian melalui blynk yang telah dibuat sebelumnya. Adapun pengujian secara fungsional dilakukan terhadap NodeMCU, dan sensor pzem diantaranya:

Pengujian NodeMCU ESP8266 ini dilakukan untuk mengetahui apakah NodeMCU terhubung pada perangkat yang lain, dan apakah sudah terkoneksi dengan jaringan internet dan terkoneksi 
dengan aplikasi Blynk. Jika lampu menyala maka NodeMCU sudah terkoneksi atau sudah terhubung.

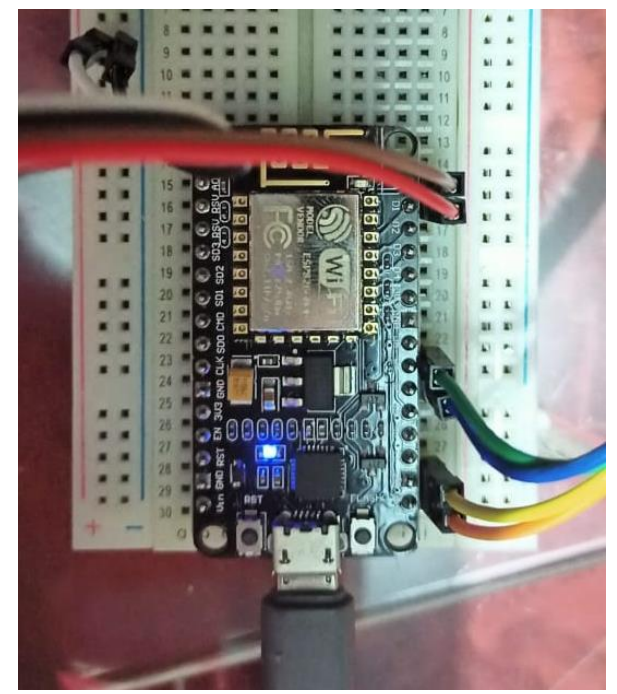

Sumber : (Maria Febrianti, 2021)

Gambar 14. Pengujian NodeMCU ESP8266

Jika NodeMCU ESP8266 belum terkoneksi oleh internet, maka aplikasi blynk belum dapat terhubung dan tidak bisa memonitoring daya listrik dan terlihat pada gambar 15. tampilan pada blynk masih offline.

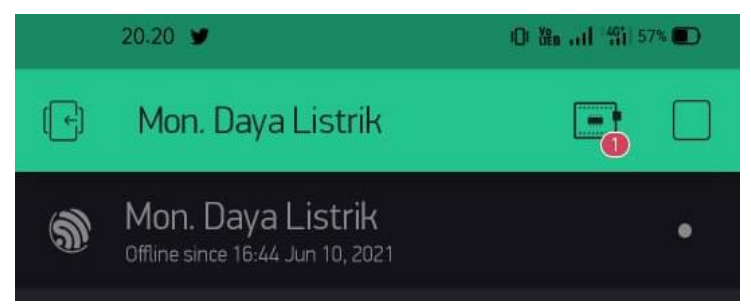

Sumber : (Maria Febrianti, 2021)

Gambar 15.Pengujian Aplikasi Blynk

Apabila NodeMCU ESP8266 sudah terkoneksi oleh internet, maka aplikasi blynk sudah dapat memonitoring daya listrik dan terlihat pada gambar 16. tampilan pada blynk sudah online.

\section{Mon. Daya Listrik

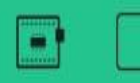

(B) Mon. Daya Listrik

Online since 20:26 Jun 10,2021

Sumber : (Maria Febrianti, 2021)

Gambar 16. Pengujian Aplikasi Blynk

Sensor PZEM-004T jika sudah terhubung oleh perangkat elektronik yang mempunyai arus listrik maka lampu pada sensor tersebut menyala.

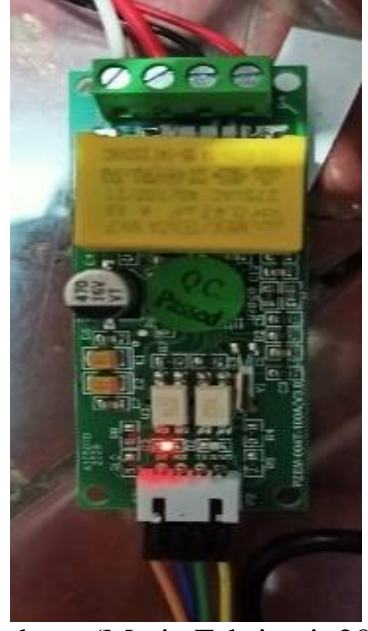

Sumber : (Maria Febrianti, 2021)

Gambar 17. Pengujian Sensor PZEM

Jika sensor Pzem sudah membaca aliran listrik pada perangkat elektronik maka akan dilihat pada serial monitoring, apabila hasil dari arus sudah terlihat atau terbaca maka sensor berjalan dengan baik.

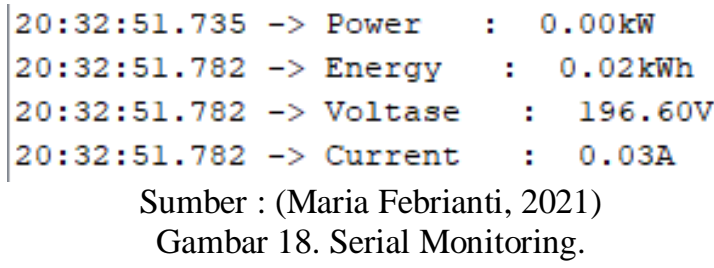

Sumber : (Maria Febrianti, 2021)

Gambar 18. Serial Monitoring.

Tabel 4. Tabel Pengujian Perangkat

\begin{tabular}{|c|c|c|c|}
\hline No & $\begin{array}{c}\text { Status } \\
\text { Perangkat }\end{array}$ & $\begin{array}{l}\text { Hasil Yang } \\
\text { Diharapkan }\end{array}$ & $\begin{array}{c}\text { Hasil } \\
\text { Pengujian }\end{array}$ \\
\hline 1 & $\begin{array}{l}\text { NodeMCU } \\
\text { ESP8266 }\end{array}$ & $\begin{array}{l}\text { Dapat } \\
\text { terkoneksi } \\
\text { internet dan } \\
\text { lampu pada } \\
\text { mikrokontroler } \\
\text { menyala. }\end{array}$ & $\begin{array}{l}{[\sqrt{ }] \text { Berhasil }} \\
{[\text { ] Gagal }}\end{array}$ \\
\hline 2 & $\begin{array}{l}\text { Aplikasi } \\
\text { Blynk }\end{array}$ & $\begin{array}{l}\text { Jika tidak ada } \\
\text { koneksi internet } \\
\text { makaada } \\
\text { pemberitahuan } \\
\text { bahwa aplikasi } \\
\text { sedang offline }\end{array}$ & $\begin{array}{l}{[\sqrt{ }] \text { Berhasil }} \\
{[\text { ] Gagal }}\end{array}$ \\
\hline 3 & $\begin{array}{l}\text { Aplikasi } \\
\text { Blynk }\end{array}$ & $\begin{array}{l}\text { Aplikasi } \\
\text { terkoneksi } \\
\text { jaringan internet } \\
\text { dan ada status } \\
\text { online }\end{array}$ & $\begin{array}{l}{[\sqrt{ }] \text { Berhasil }} \\
{[\text { ] Gagal }}\end{array}$ \\
\hline 4 & $\begin{array}{l}\text { Sensor } \\
\text { PZEM- } \\
004 T\end{array}$ & $\begin{array}{l}\text { Lampu pada } \\
\text { senor berkedip } \\
\text { apabila ada } \\
\text { aliran listrik } \\
\text { yang terbaca } \\
\text { oleh sensor }\end{array}$ & $\begin{array}{l}{[\sqrt{ }] \text { Berhasil }} \\
{[\text { ] Gagal }}\end{array}$ \\
\hline
\end{tabular}




\begin{tabular}{|c|c|c|c|}
\hline No & $\begin{array}{c}\text { Status } \\
\text { Perangkat }\end{array}$ & $\begin{array}{c}\text { Hasil Yang } \\
\text { Diharapkan }\end{array}$ & $\begin{array}{c}\text { Hasil } \\
\text { Pengujian }\end{array}$ \\
\hline 5 & $\begin{array}{l}\text { Serial } \\
\text { Monitoring }\end{array}$ & $\begin{array}{l}\text { Jika sensor } \\
\text { berjalan maka di } \\
\text { serial } \\
\text { monitoring akan } \\
\text { terlihat berapa } \\
\text { arus, power, } \\
\text { voltage, dan } \\
\text { energy pada } \\
\text { perangkat } \\
\text { elektronik yang } \\
\text { terbaca. }\end{array}$ & $\begin{array}{l}{[\sqrt{ }] \text { Berhasil }} \\
{[\text { ] Gagal }}\end{array}$ \\
\hline
\end{tabular}

Sumber: (Maria Febrianti Pela, 2021)

\section{KESIMPULAN}

Dari beberapa tahap perancangan, pembuatan dan pengujian yang telah dilakukan. Dapat diambil kesimpulan sebagai berikut:

Prototype sistem monitoring penggunaan daya listrik dengan aplikasi Blynk dapat berfungsi memonitoring daya, sehingga bisa mengetahui berapa power, energy, voltase, dan current pada setiap perangkat elektronik-nya. Prototype ini dapat digunkan sebagai sistem monitoring dalam melakukan penghematan daya listrik pada perangkat elektronik setiap harinya tanpa tidak perlu takut melunjaknya pembayaran listrik setiap bulan karna pemakaian yang tidak terkontrol. Syarat utama dari pengendalian alat ini adalah koneksi internet yang terhubung ke perangkat hardware yaitu NodeMCU dan smartphone tersebut sudah ter-install aplikasi Blynk. Pemilik rumah dapat memonitoring langsung dari aplikasi Blynk saat daya listrik, agar pemakaian setiap harinya tidak melebihi kapasitas dan akan termonitoring secara langsung pada alat yang telah dibuat. Prototype sistem monitoring daya listrik menggunaan aplikasi Blynk ini dapat membantu dan mempermudah pemilik rumah dalam memonitoring daya listrik pada saat pemilik rumah sedang tidak berada dirumah.

\section{DAFTAR PUSTAKA}

Andri Firmansyah DAP. 2019. SIGMA - Jurnal Teknologi Pelita Bangsa. 10: 1-9.

Anwar S, Artono T, Nasrul N, Dasrul D, Fadli A. 2020. Pengukuran Energi Listrik Berbasis PZEM-004T. Pros. Semin. Nas. Politek. Negeri Lhokseumawe 3: 272.

Budi Prayitno, Pritasari Palupiningsih HBA. 2019. Prototipe Sistem Monitoring Penggunaan Daya Listrik Peralatan Elektronik Rumah Tangga Berbasis Internet of Things. Petir 12: 72-80.

Dalimunthe RA. 2018. Pemantau Arus Listrik Berbasis Alarm Dengan Sensor Arus Menggunakan Mikrokontroller Arduino Uno. Semin. Nas. R. 2018 9986: 333-338.

Deny Nusyirwan A. 2019. Jurnal Ilmiah Pendidikan Teknik Kejuruan ( JIPTEK ). J. Ilm. Pendidik. Tek. Kejuru. 101: https://jurnal.uns.ac.id/jptk.

Ely P. Sitohang, Dringhuzen J. Mamahit NST. 2018. Rancang Bangun Catu Daya Dc Menggunakan Mikrokontroler Atmega 8535. J. Tek. Elektro dan Komput. 7: 135-142.

Habibi FN, Setiawidayat S, Mukhsim M. 2017. Alat Monitoring Pemakaian Energi Listrik Berbasis Android Menggunakan Modul PZEM-004T. Pros. Semin. Nas. Teknol. Elektro Terap. 2017 01: 157-162.

Handarly D, Lianda J. 2018. Sistem Monitoring Daya Listrik Berbasis IoT (Internet of Thing). JEECAE (Journal Electr. Electron. Control. Automot. Eng. 3: 205-208.

Pangestu AD, Ardianto F, Alfaresi B. 2019. Sistem Monitoring Beban Listrik Berbasis Arduino Nodemcu Esp8266. J. Ampere 4: 187.

Pressman RS. 2010. Software Engineering A Practitioner's Approach, Seventh Ed. 930 p.

Ratnasari T, Senen A. 2017. Perancangan Prototipe Alat Ukur Arus Listrik Ac Dan Dc Berbasis Mikrokontroler Arduino Dengan Sensor Arus Acs-712 30 Ampere. J. Sutet 7: 28-33.

Santoso Hb, Prajogo S, Mursid Sp. 2018. Pengembangan Sistem Pemantauan Konsumsi Energi Rumah Tangga Berbasis Internet of Things (IoT). ELKOMIKA J. Tek. Energi Elektr. Tek. Telekomun. Tek. Elektron. 6: 357.

Satriadi A, Wahyudi, Christiyono Y. 2019. Perancangan Home Automation Berbasis NodeMCU. Transient 8: 64-71.

Suwitno. 2016. Mendesain Rangkaian Power Supply pada Rancang Bangun. J. Electr. Technol. 1: $1-7$. 